\title{
On Techniques for Stabilising and Photographing Skulls
}

\author{
PATRICIA SMITH AND GEOFFREY WALKER \\ Laboratory of Physical Anthropology, Department of Anatomy and Embryology, \\ Hebrew University-Hadassah Medical and Dental Schools, Jerusaleum, \\ Israel, POB 1172, and Biometric Laboratory, University of Michigan \\ Dental School, Ann Arbor, Michigan 48104
}

\section{KEY WORDS Skull photography Craniostat.}

\begin{abstract}
The design and use of a small light portable craniostat is described. Made of clear polystyrene, with adjustable pegs of the same material, the device is small, light, unbreakable and easily portable. It facilitates rapid and stable positioning of skulls in any position for study of photography.
\end{abstract}

Conventional methods of positioning skulls for photography are time consuming and involve some risk of damage to the specimens. Establishing the correct relationship of the mandible to the skull, and fixing it in the desired position for study or photography poses a further problem, especially when the mandible is incomplete. Figures 1 to 3 show unretouched photographs of skulls taken in a skull holder devised by the authors, that facilitates safe, rapid, and easy positioning of skulls in a variety of positions. The skull holder made of clear plastic (polystyrene) is light, unbreakable and based on the pegboard principle (fig. 4). It consists of three parallel layers of polystyrene, with holes drilled through the upper two levels 1.5 cms apart. Rigid pegs are placed in these holes at the desired interval to support the skull. By varying the distance between the pegs, or using pegs of different lengths, skulls of various shapes and sizes can be safely positioned. Figures 1 to 3 were taken with the skull upside down in the skull holder. In this position the mandible can be easily balanced on the skull, with the teeth in correct occlusion without resource to fixation. The clear pegs are barely seen and the entire skull outline is clearly visible. Since the evidence is extremely stable, the skull can be rotated on the pegs, or alternatively the whole device, with the skull in position moved around as desired. It is then simple to align the skull at the desired angle to the camera, using a right angle, or rectangular frame if desired. 


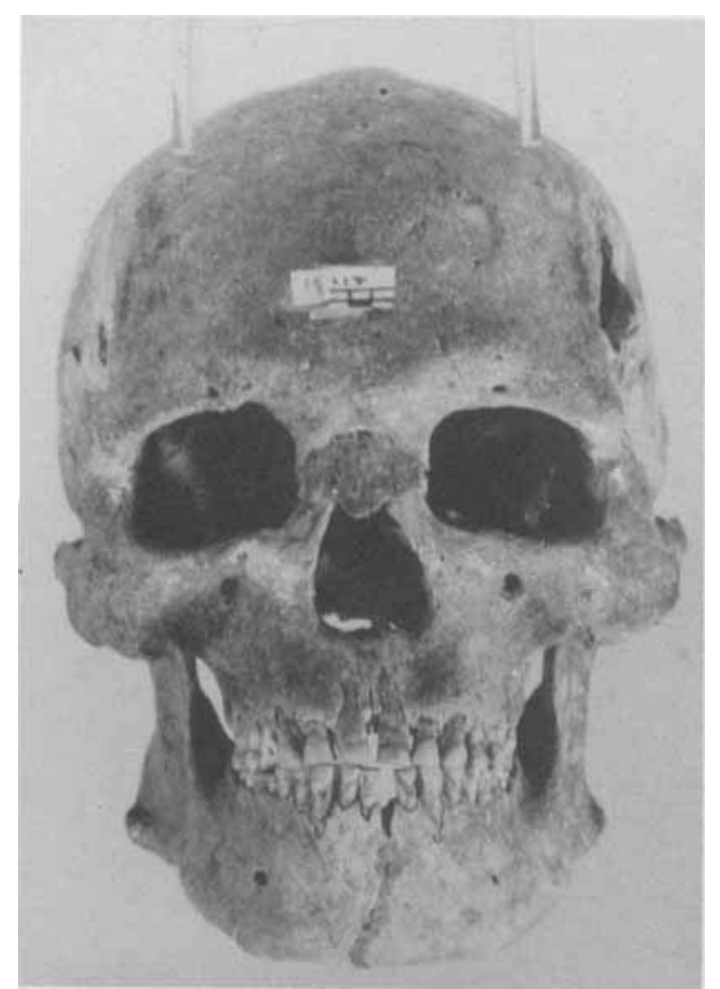

Fig. 1 Frontal view of skull (taken with skull upside down).

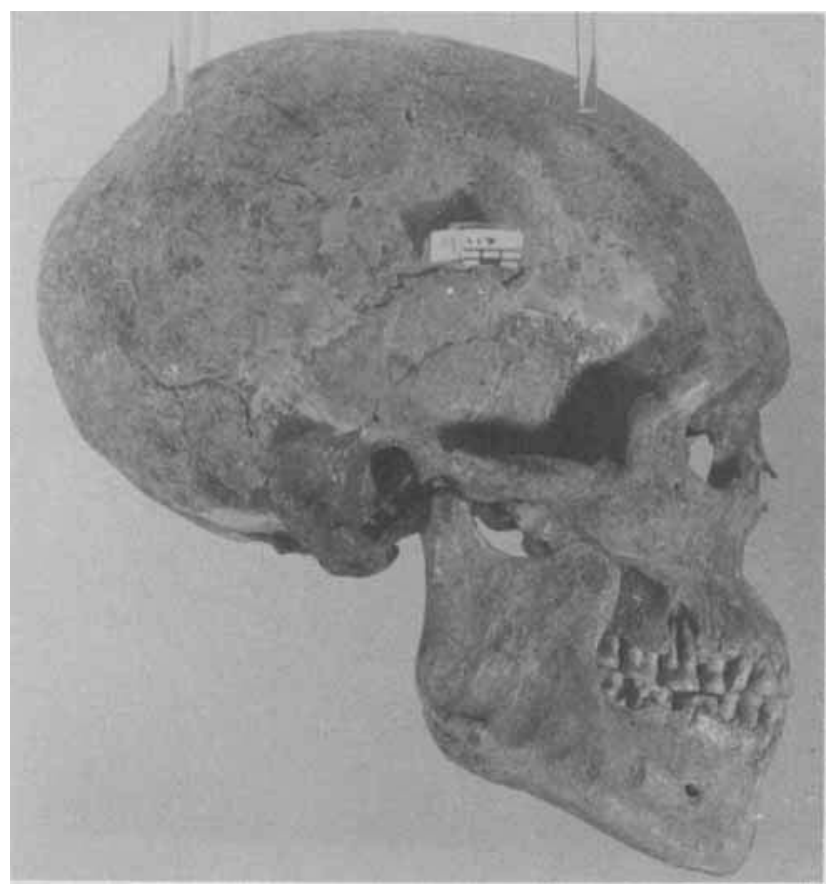

Fig. 2 Lateral view of skull. 


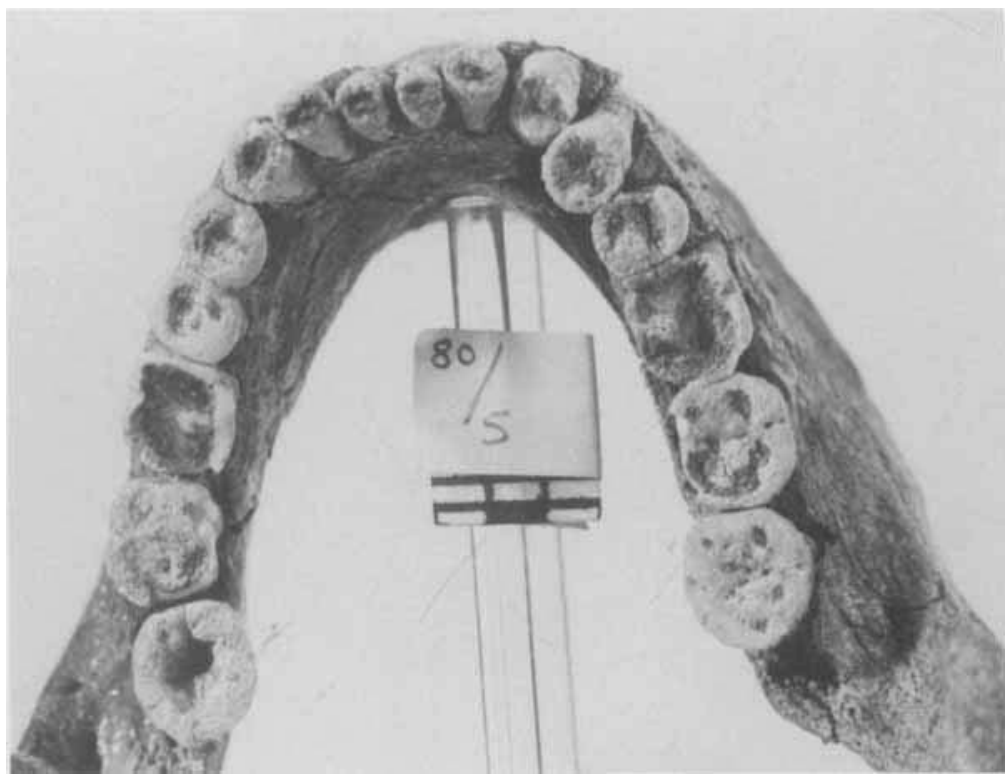

Fig. 3 Occlusal view of mandiłse, taken with mandible balanced vertically on pegs.

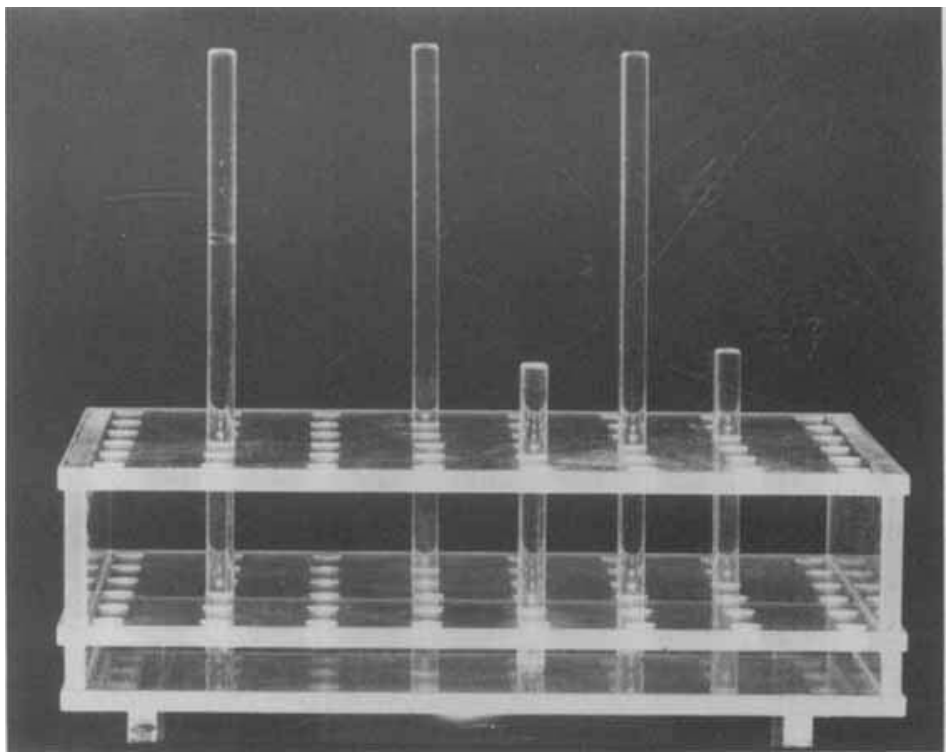

Fig. 4 Skull holder, with pegs of different lengths 